\title{
Relationship between the Onset Age of Bilingualism and Development of Cognitive Control among Nigerians
}

\author{
Yasir Bdaiwi Jasim Al-Shujairi (Corresponding author) \\ Faculty of Modern Language and Communication, University Putra Malaysia \\ 43400 Serdang, Selangor, Malaysia \\ E-mail: yasir.bdaiwi.jasim1990@gmail.com \\ Jamila AbdulAzeez Buba \\ Faculty of Modern Language and Communication, University Putra Malaysia \\ 43400 Serdang, Selangor, Malaysia \\ E-mail: Jamila_abdulazeez@yahoo.com \\ Mohammed Sani Ya'u \\ Faculty of Modern Language and Communication, University Putra Malaysia \\ 43400 Serdang, Selangor, Malaysia \\ E-mail: elmuhsan@gmail.com
}

Doi:10.7575/aiac.alls.v.7n.1p.114

URL: http://dx.doi.org/10.7575/aiac.alls.v.7n.1p.114
Received: 04/09/2015

Accepted: 10/11/2015

\begin{abstract}
An increasing body of studies suggests that bilingual persons are better than monolinguals on a variety of cognitive measures. Thus, the present study investigates the relationship between the onset age of bilingual and the development of cognitive control among Nigerians. 10 bilingual students studying at University Putra Malaysia have been selected to participate in this study. They are divided into two groups: 5 early and 5 late bilinguals. The data are collected using online English proficiency test and E-prime software as instruments. Both groups are examined for English proficiency and performance on a flanker task. The result demonstrates that early bilinguals are more proficient in English than late bilinguals. Moreover, early bilingual performs better than late bilingual on flanker task. Based on these findings, it can be concluded that being early active bilinguals tend to have greater advantages in cognitive control and higher language proficiency.
\end{abstract}

Keywords: onset age, bilingualism, and cognitive control

\section{Introduction}

Language propensity (Aptitude) is theorized as a mixture of cognitive and perceptual capacities that are very much advantageous in second language acquisition (SLA) (Doughty et al., 2007). Carroll (1993) sees this pattern of capacities (p. 675) and maintained that they were to some extent inborn, fairly steady and moderately long-term characters. While specialists and novice would equally concur the common view of aptitude as a special ability for language, the speculative paradigm behind this popular idea has continued to be somewhat indefinable in the SLA scholarship. Although there is some understanding that language aptitude includes diverse cognitive abilities, it has been theorized in many ways in SLA, and separately they have distinctive implications at the measurement level.

An increasing body of studies suggests that bilingual persons are better than monolinguals on a variety of cognitive measures (Craik, \& Ryan, 2006). These advantages, which have been considered as advantages in cognitive control, have been documented across the lifespan. Improved cognitive control among bilinguals has been observed in bilingualexposed infants and toddlers (Poulin-Dubois, et al., 2011) bilingual preschool children, young adults and older adults (Bialystok, Craik, \& Freedman, 2007). Further, cognitive controls advantages of bilingualism have been demonstrated using multiple cognitive tasks and found out that among bilinguals speaking a variety of language pairs, others are balanced bilinguals while other are not, suggesting that these effects are not limited to a single task or particular language pairing (Thompson, \& Ungerleider, 2010).

Studies on progressive effect of bilingualism on executive control as reported by Bialystok, 2007 leaves some question on how much bilingual experience is needed to appreciate these benefits. Normally, the research picks bilinguals who are very eloquent in the two languages and are using both frequently. This categorization of bilingualism is largely centered on an evaluation of factors as commencement age of second language (L2) acquisition, competence in the second language, and extent of acquaintance to the L2. While these variables regarding bilingual history have been indicated in influencing characteristics of language and comprehension development (Kovelman, Baker \& Petitto, 2008), their function in influencing the relation between bilingualism and cognitive consequences is not determined. 
Shared elucidation for the bilingual effect on executive control is that bilinguals are required to direct attentiveness to two existing organisms, hence employ the executive control network for this purpose (Abutalebi \& Green, 2007). Continuous involvement of this control system in handling the two languages strengthens the system, resultant in early development in children and further efficient performance in adulthood. For instance, bilingual children and adults do better than their monolingual peers in responsibilities that involve cognitive plasticity (Bialystok, Craik \& Ruocco, 2006), and reserve of distracting or conflicting information (Bialystok \& Shapero, 2005). In all these reports, bilinguals were designated to be persons who had used two languages to a high degree of competence for most of their lives.

This current study is aimed to relate bilinguals who commenced early or late in active usage of two languages for their task controls. The onset age of bilingualism therefore, was expressed as the age at which the bilinguals started using both languages on a regular base. This can be said to be unusual from erstwhile studies that use age of L2 acquisition or migration age as the onset measure of bilingualism (Birdsong, 2005). Irrespective of the age at what stage a second language was learnt, the current analysis assessed the age at which that language became a functional part of the individual's linguistic catalogue. A prior onset age of functional bilingualism also shows longer history of using two languages in a number of young adults. The choice of Nigerian students was based on two main reasons; first the Nigerian state that was created in 1914, as an act of British colonialism, by the unification of two surviving British colonial states, the Protectorate of Northern Nigeria and the Colony and Protectorate of Southern Nigeria was 100 years old on the $1^{\text {st }}$ day of January 2014. It is will be most suitable at this point to explain the meaning and the consequence of 'amalgamation'. Understandably, amalgamation may be seen as the uniting or inclusion of two groups or units into one, with the outcome that together they tend to be, and are substituted by a new group or unit. Therefore, with the 1914 amalgamation, both the Northern and Southern Protectorates of Nigeria ended its existence as distinct legal units and remained as a single unit called the Colony and Protectorate of Nigeria.

Secondly, with this political development of the country, and the effects of the colonialism and their administration, Nigeria is today viewed as having three major regions, The North, South and West. The latter two regions came into contact with western education earlier than the North, thus educationally more developed than the North and are exposed to English at an early age there by qualifying them as early bilinguals.

This study therefore hypothesized that; bilingual adults with an earlier commencement age of functional bilingualism were likely to perform better on their control task than the bilinguals who commenced using two languages late in life. The age considered in this study for bilinguals early or late was chosen to be 15 years old as early and above 15 as late. Earlier research reported support for a critical hypothesis suggested this period to be around the age of puberty (Johnson $\&$ Newport, 1989; DeKeyser, 2000).

\subsection{Objectives of the study}

The main objective of this study is:

- To Asses the cognitive advantages in bilinguals, and the influences associated to it.

- To compares bilinguals who started early or late in actively using two languages for their performance.

- To identify different levels of bilingual's English proficiency.

\subsection{Statement of problem}

Correlation amongst onset age of bilingualism and improvement of cognitive control has been acknowledged by contemporary research, reporting a encouraging effect of bilingualism on executive control (Bialystok, 2007). Classification of bilingualism is mostly founded on an evaluation of the following factors as, onset age of second language (L2) acquisition, competency of the second language, and length of exposure to the L2.

While these variables regarding bilingual account have been presented to affect characteristics of language and literacy development (Kovelman, Baker \& Petitto, 2008), their role in regulating the relationship between bilingualism and cognitive consequences is unknown in the study area.

Emmorey, Luk, Pyers \& Sebastian-Galls (2008), reported findings on a bilingual benefit in cognitive elasticity by using Flanker tasks in young and middle-aged adults. The relationship between age of becoming active bilingual and English competence is constant with a large-scale. Study reported by Hakuta, Bialystok, and Wiley (2003) states that increase in age of second language acquisition was correlated with declining second language proficiency through lifetime. Thus, the present analysis is an attempt to demonstrate the bilingual consequence on executive control among Nigerian bilinguals studying in University Putra Malaysia.

\subsection{Research questions}

This study intends to answer the following questions;

1- How the onset age of bilingual performance relate to the cognitive control?

2- What is the relationship between the age of active bilingualism and English proficiency?

\subsection{Significance of the study}

This study, the onset age of bilingualism was projected to allow bilinguals to be aware of the significance of the prior onset of functioning bilingualism, which is to associate it with better functioning in English sensitive vocabulary. It is therefore, inevitable that the early bilinguals became competent in their second language at earlier age than the late bilinguals, confusing length of time being bilingual and age of acquirement of a second language. The study is also likely to encourage bilinguals to think critically of the tasks they are involved with. 


\section{Literature review}

Several researchers have explored the relationship between the onset age of bilingualism and cognitive development. Gigi \& Bialystok (2014), for example, have noted in their study that late bilingual participants had been using two languages for only a half of their lives, performed more like monolinguals on the executive tasks. They also had significantly lower scores in English proficiency tests. These comparison provided evidence for the view that there is a relationship between onset age of actively practicing bilingualism and the size of effects on performance. In this study, analysis conducted 100 sample of participants indicated a positive relationship between these two variables. Moreover, the result has also indicated that early bilinguals became proficient in their L2 at an earlier age than the late bilinguals. In contrast, Bialystok et al. (2014), in their study executed with function test to discover the effects of bilingualism on the age of onset and progression of Mild Cognitive Impairment (MCI) and Alzheimer Disease (AD) found that there was a significant effects of bilingualism on birth age of onset and age of first clinic appointment such that bilinguals diagnosed with $\mathrm{MCI}$ and $\mathrm{AD}$ were older than their monolingual counterparts when they began to show symptoms. The implication of the result is that there is late-life benefit from early bilingual exposure and continued bilingual practice.

Considerably, the constant involvement of the executive control system in managing attention to two languages fortifies that system, resulting in earlier development in children and more effective functioning in adulthood. For example, bilingual children and adult perform better than their monolingual peers in tasks that require cognitive flexibility (e.g. dimensional card sorting task for children and adult, Bialystok, Craik \& Ruocco, 2006; Bialystok \& Martin, 2004) and inhibition of distracting or conflicting information (e.g. appearance-reality resolution in children, Bialystok \& Shapero, 2005; Simon task I children and older adults, Bialystok, Craik, Klein \& Viswanathan, 2004; Martin-Rhee \& Bialystok, 2008; behavioural antisaccade task in young and older adults, Bialystok, Craik \& Ryan, 2006; Bialystok \& Viswanathan, 2009; and flanker task in young and middle-aged adults, Costa, Hernandez \& Sebastian-Galle, 2008;Emmorey, Luk, Pyers \& Bialystok, 2008.

However, in another study, Thomas et al. (2014), analyzed information collected from the participants to investigate whether Bilingualism influence Cognitive aging, and the types of bilingualism (early versus late acquisition). They suggested that determination of differential effects depends on childhood IQ. Therefore, Individual with high intelligence seems to benefit more from early acquisition, but neither of the group showed negative effect. Accordingly, early and late acquisition of a second language might have different effects on frontal executive function.

While different factors associated with the reported advantages found in fully bilingual children for metalinguistic awareness and executive control, level of proficiency in the language testing is related to performance in metalinguistic tasks. This is evident in Bialystok \& Barac (2012), in their study 'Emerging Bilingualism'. The findings demonstrated a benefit of bilingualism on children's executive control. It also reveals the relationship between bilingualism and metalinguistic performance. Similarly, the results discover the mechanism by which bilingualism affects cognitive and linguistic outcomes.

On the other hand, Unworthy (2012), examined two groups of bilingual children (English/Dutch and English/Greek) in order to investigate the role onset and input quantity on the acquisition of grammatical gender as marked of definite determiners. In the sample of English/Dutch children, cumulative length of exposure was also observed to significantly correlate with age of testing and age of onset.

Gigi Luk, et at. (2011), conducted a study with group of bilinguals with age range of about 20 years old, the study was done to examine the English proficiency for bilingual adults and also young monolinguals on a flanker task. The researcher found out that both early monolinguals and bilinguals demonstrated similar proficiency level, as they were all proficient than the late bilinguals. After the data for the study was analyzed, it was found out that, the onset age of active bilingualism was negatively correlated for English proficiency and positively correlated with flanker task. This shows that there is an advantage in being bilingual, because of the cognitive control and higher language proficiency.

\section{Methodology}

\subsection{Sample selection and size}

In selecting subjects of the current study, a purposive sampling method was used, because it is one of the most excellent methods to obtain a representative sample. This type of method is usually cost and time economic. 10 Nigerians postgraduate students at UPM University in a multicultural country Malaysia has been taken to participate in this study. The 10 participants were divided into two groups. First group contains 5 early bilinguals, whereas the second group contains 5 late bilinguals. All the bilinguals were asked to report the age at which they began to use both languages actively and regularly on a daily basis. The reporting age was considered to be the onset age of active bilingualism. Early bilinguals reported that they started active bilingualism before 10, and late bilinguals reported that their onset age of active bilingualism was after the age of 10 .

Table 1 and 2 below show the age and the gender of all participants. The tables also indicate the onset age of active bilingualism. Hence, bilingualism could be seen as the age that participant starts to use L2 in her/his daily life situation. Besides, the proficiency level score of all participants has been presented. Participant using the following link took the proficiency test online http://www.transparent.com/learn-english/proficiency-test.html. 
Table 1. Early bilingual participants

\begin{tabular}{cccccc}
\hline No. & Participants & Age & Gender & $\begin{array}{c}\text { Proficiency } \\
\text { level }\end{array}$ & $\begin{array}{c}\text { Age of } \\
\text { active } \\
\text { bilingualism }\end{array}$ \\
\hline 1 & Lilian & 31 & Female & $90 \%$ & 3 \\
\hline 2 & Grace & 30 & Female & $80 \%$ & 4 \\
\hline 3 & Daniel & 32 & Male & $84 \%$ & 4 \\
\hline 4 & Tope & 26 & Male & $87 \%$ & 4 \\
\hline 5 & Ajadi & 30 & Male & $83 \%$ & 5 \\
\hline & & Average & & $\begin{array}{c}\text { Average } \\
84.5 \%\end{array}$ & $\begin{array}{c}\text { Average } \\
4\end{array}$ \\
\hline
\end{tabular}

Table 2. Late bilingual participants

\begin{tabular}{cccccc}
\hline No. & Participants & Age & Gender & $\begin{array}{c}\text { Proficiency } \\
\text { level }\end{array}$ & $\begin{array}{c}\text { Age of } \\
\text { active } \\
\text { bilingualism }\end{array}$ \\
\hline 1 & Jamila & 33 & Female & $76 \%$ & 12 \\
\hline 2 & Adamu & 28 & Male & $70 \%$ & 14 \\
\hline 3 & Abdullahi & 38 & Male & $71 \%$ & 19 \\
\hline 4 & Habib & 30 & Male & $71 \%$ & 15 \\
\hline 5 & Mohammad & 31 & Male & $77 \%$ & 15 \\
\hline & & Average & & Average \\
& 32 & & & $\begin{array}{c}\text { Average } \\
13 \%\end{array}$ \\
\hline
\end{tabular}

All the participants have been given an English proficiency test to identify their level of proficiency. The test was an Internet based where the participants individually asked to do it online and send their score report on Email.

\subsection{Instruments}

To make the result more accurate and valid, this study used E-prime software as an instrument.

The computers have become a significance tool to design many kinds of experiments. E-prime has been created to simplify the conception of experiments. It has been developed by PST Net, offers a user-friendly interface that makes typical experiments easy to build. This study shows how to create an experiment effortlessly with E-prime, followed by an example.

\subsection{Procedure}

Flanker task

The flanker task was adapted from Eriksen and Eriksen (1974) and Bunge, Dudukovic, Thomason, Vaidya and Gabrieli (2002). All participants were asked to indicate the congruent and incongruent chevrons by pressing 1 and 9 respectively located on the keyboard. In congruent trials, there was an array of five, four and three chevrons all pointing in the same direction. For incongruent trails, the flanking chevrons pointed in the opposite direction. Successful response required the recruitment of executive control to focus on the target chevrons and avoid being distracted by the extraneous conflicting flankers.

Each block started with 6 practice trails randomly. All participants were given the choice of getting more practice if they like, but none of them made such request. Both RT and ACC were measured, but only trials associated with a correct response were included in the RT analysis. Sample stimuli are presented in figure 1 below. 


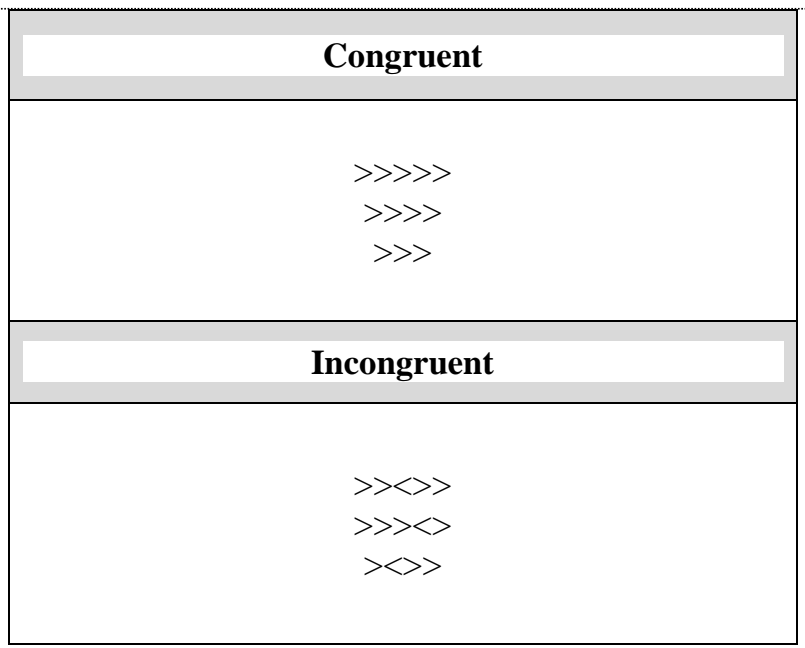

Figure 1. Sample stimuli of Flanker task

The software program which has been used in this procedure is E-prime. It has been designed to facilitate the conception of any experiment that uses a computer as an edge between the subject and the experimenter. It can also run the experiment, collect the results and do some basic data analysis. The five programs that constitute E-prime are EStudio, E-Run, E-Data Aid, E-Merge and E-Recovery.

\subsection{Data collection}

The data has been collected by using E-Studio. It is a subprogram of E-prime devoted to create and run experiments. It is a major program that comes with E-prime. Figure 2 shows the trail list with 12 stimuli and each one has been repeated twice through the experiments. The stimulus presented randomly to the participants.

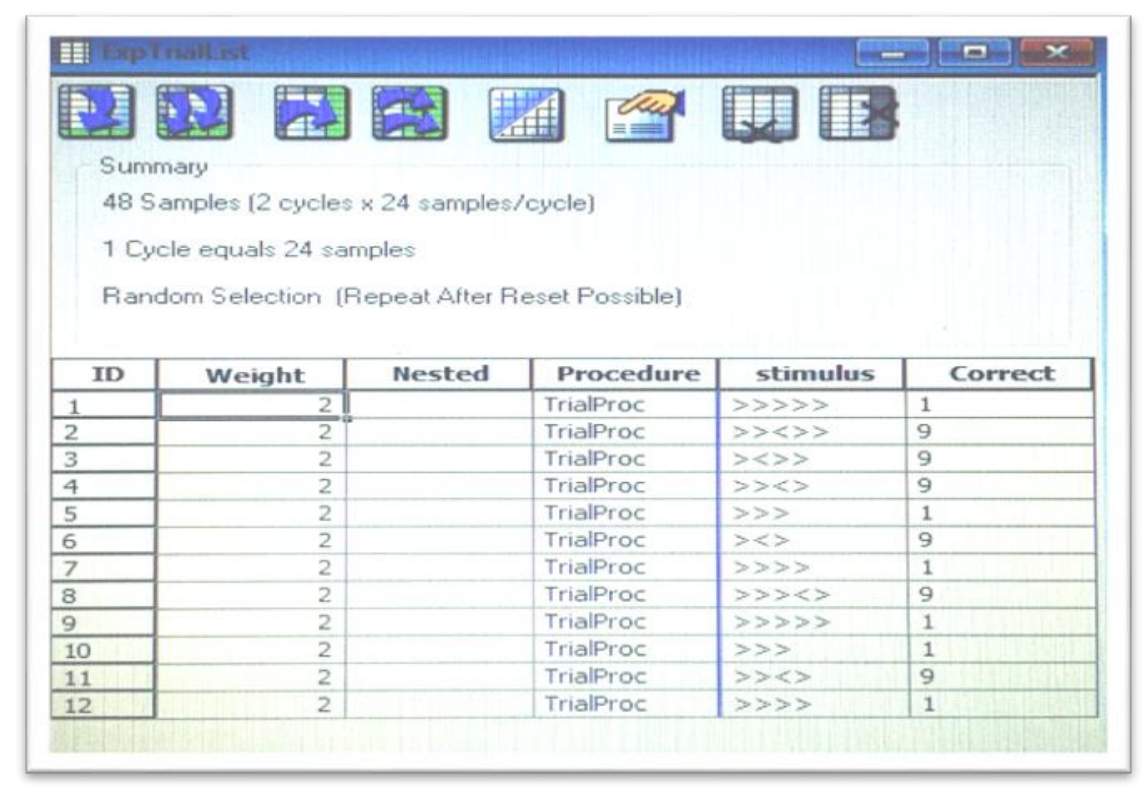

Figure 2. The trial list with 12 stimulus of the experiment

\subsection{Data analysis}

This paper used E-Data Aid program to analyze data. It shows the data collected. As presented in figure 3 , it uses the file created by running the experiment in E-Studio. E-Data Aid offers important functions: identify, modify, and analyze the data. What we need to illustrate in this research are the accuracy and the response time of both congruent and incongruent stimulus for all participants. Look at table 3 below.

Table 3. Analyzing the data of participant 9 (Habib) by using E-Data Aid

\begin{tabular}{ccccccccccc}
\hline Sub & SE & Trial & C & ACC & CRESP & S.OnsetTime & S.RESP & S.RT & S.RTTime & STM \\
\hline 9 & 1 & 1 & 1 & 1 & 1 & 76796 & 1 & 1090 & 77890 & $>>>>$ \\
\hline 9 & 1 & 2 & 1 & 1 & 1 & 78915 & 1 & 630 & 79540 & $>>>$ \\
\hline 9 & 1 & 3 & 9 & 1 & 9 & 80567 & 9 & 740 & 81310 & $>>\langle>$ \\
\hline 9 & 1 & 4 & 1 & 1 & 1 & 82335 & 1 & 540 & 82870 & $>>>$ \\
\hline 9 & 1 & 5 & 1 & 1 & 1 & 83904 & 1 & 590 & 84490 & $>>>>$ \\
\hline 9 & 1 & 6 & 9 & 1 & 9 & 85522 & 9 & 840 & 86360 & $>\langle>>$ \\
\hline
\end{tabular}




\section{Findings and Discussion}

After analyzing the data, it is observed that the participants responded differently in accordance with their level of proficiency in displaying cognitive control. This can be justified in their time taken (reaction time) as well as how accurate they are (accuracy) while performing both congruent and incongruent stimulus in the given flanker tasks. The tables below illustrate the stimulus accuracy and reaction time for the early and late bilinguals, average proficiency level and average age of active bilingualism, and finally average accuracy and reaction time. In terms of the accuracy and the reaction time illustrated in the table below, it should be noted that the higher the score of the participant in accuracy, the better he/she performed. However, in terms of reaction time, the lower the score of the participant (time spent while performing stimulus task), the better the performance and vice versa.

Table 4. The stimulus ACC and RT for early bilingual participants

\begin{tabular}{rccccc}
\hline No. & Participants & ACC-Cong & ACC-Incong & RT-Cong & RT-Incong \\
\hline 1 & Lilian & 1.00 & 0.96 & 488.75 & 595.00 \\
\hline 2 & Grace & 1.00 & 0.96 & 540.98 & 598.67 \\
\hline 3 & Daniel & 1.00 & 0.96 & 484.58 & 541.25 \\
\hline 4 & Tope & 0.96 & 1.00 & 498.75 & 523.75 \\
\hline 5 & Ajadi & 0.96 & 0.96 & 438.75 & 473.75 \\
& & 0.98 & 0.96 & 490.36 & 546.48 \\
\hline
\end{tabular}

This table indicates the performances of early bilinguals in a given stimulus tasks. From the above table, it can be deduced that 'Tope' is the best among the participants. Although he got lower scores in congruent in both ACC and RT, he scored better in incongruent in both ACC and RT. Furthermore, Lilian, Grace and Daniel have similar scores in ACC both in congruent and incongruent, but differs respectively in RT in both congruent and incongruent. Accordingly, 'Ajadi' has the least scores compared to other participants.

Table 5. The stimulus ACC and RT for late bilingual participants

\begin{tabular}{rccccc}
\hline No. & Participants & ACC-Cong & ACC-Incong & RT-Cong & RT-Incong \\
\hline 1 & Jamila & 0.92 & 1.00 & 538.33 & 550.00 \\
\hline 2 & Adamu & 1.00 & 0.92 & 530.42 & 674.58 \\
\hline 3 & Abdullahi & 0.96 & 1.00 & 581.67 & 570.83 \\
\hline 4 & Habib & 1.00 & 1.00 & 587.08 & 672.92 \\
\hline 5 & Mohammad & 0.96 & 0.96 & 526.67 & 537.08 \\
& & 0.96 & 0.97 & 552.83 & 601.08 \\
\hline
\end{tabular}

The table above shows the performances of late bilinguals in stimulus tasks given to them. If one examined the scores critically, it can be concluded that Muhammad, though, less than Habib in ACC both in congruent and incongruent is the best participant, followed by Habib. In fact, Muhammad scored marvelously in RT both congruent and incongruent. Contrariwise, Habib scored better than Muhammed in ACC in both congruent and incongruent. Jamila and Adamu almost have the same scores interchangeably in ACC both in congruent and incongruent. They however have little bit differences in RT (congruent and incongruent). Abdullahi seems to be last participant even though he scored better in ACC incongruent.

Table 6. Average age, proficiency level, and Age of active bilingualism of participants.

Average Age Proficiency level Age of active bilingualism

\begin{tabular}{cccc}
\hline Early bilingual & 30 & $84.5 \%$ & Average \\
& & & 4 \\
\hline Late bilingual & 32 & Average & Average \\
& & $73 \%$ & 15 \\
\hline
\end{tabular}

The above table reveals the average age, average proficiency level and average age of active bilingualism of both early and late bilinguals. From the data presented in the table, it can easily be inferred that early bilinguals are better than 
their late bilingual counterparts in proficiency tests given to them. This is not far from the fact that early bilinguals were earlier exposed to second language knowledge. Therefore, they are in a better position to excel in language proficiency tasks better than their late bilingual counterparts. Their familiarity with both spoken and written language right from their childhood age is therefore earns them with the ability to communicate fluently and to write correctly. Unlike early bilinguals, late bilinguals only exposed to language at their later ages mostly in school settings. The finding coincides with the previous literature of bilingual research, especially different studies conducted by Bialystok and his colleagues.

Table 7. Average accuracy and reaction time for both groups.

\begin{tabular}{lcccc}
\hline & ACC-Cong & ACC-Incong & RT-Cong & RT-Incong \\
\hline Early bilinguals & 0.98 & 0.96 & 490.36 & 546.48 \\
\hline Late bilinguals & 0.96 & 0.97 & 552.83 & 601.08 \\
\hline
\end{tabular}

The table above presents the summary of the average performances in both the accuracy and the reaction time of the early and the late bilingual participants. The story remains the same in cognitive performances. Considering the above topic, it could be concluded that early bilinguals performed well in cognitive activities compared to late bilinguals. It is noticeable that early bilinguals are seemed to be balanced bilinguals, and perhaps are children of educated elites in Nigeria. In fact, they are exposed to different cognitive activities both in schools and at home. This will obviously familiarize them with accuracy in cognitive activities like this stimulus flanker tasks. In addition, they possess materials like computers, games etc which undoubtedly help them to perform cognitive activity with high accuracy and easement. However, late bilinguals lack these opportunities, which are not unconnected to their lower scores in the given tasks. These inadequacies of learning materials coupled with lack of exposure to cognitive activities will not augur well with late bilinguals in their later endeavors, unless effective measures are taken. Accordingly, there are number of recent literature that have been found supportive to this findings. For instance, Bak, et al (2014), who studied the influence of cognitive aging in early and late bilinguals found out that early bilinguals perform a given tasks with high intelligence as compared to late bilinguals, while neither of them showed negative effect. In the same vein, Kalia, et al. (2014) found a similar findings which concur the findings of this study. While investigating the influence of age of exposure and language proficiency, findings of their study demonstrated that late bilinguals exhibited disadvantage in accuracy for a tasks given to them, while their early bilinguals counterparts performed a given tasks with high accuracy.

\section{Conclusion}

Observing the findings presented in tables 4 and 5 above we find that, bilinguals who are active in the usage of the language for a long time showed less RT in the experiment. Again in both the bilingual groups RTs over the congruent chevrons are less than in the incongruent chevrons. Another issue that we observed was that, the early bilinguals were more efficient in the Flanker task than the late bilinguals this is evident from the reaction time of both groups. While the RT of the early bilinguals in both the congruent and the incongruent is 490.36 and 546.48 respectively, the late bilinguals RT was 552.83 for congruent and 601.08 for incongruent.

The correlation consideration of the two groups on task performance established to us that early developing bilingualism, together with longer bilingual proficiency, are very important pointers to higher competence in the language and greater cognitive control. The group evaluations therefore, offer some support for the opinion that there is relationship between onset age of active practicing bilinguals and cognitive control as testified in the literature (Bialystok \& Barac, 2012, Unsworth 2012).

\subsection{Limitations and recommendations}

This study has its limitation in two aspects. First, there were a small number of participants and that may limit the generalization. For further studies, it is advisable to involve a large number of participants to make a strong claim based on the findings. Second, one task which is Flanker task was used to collect the data from participants. Using various tasks will ensure the reliability and strengths the validity of the findings.

\section{Reference}

Adesope, O. O., Lavin, T., Thompson, T., \& Ungerleider, C. (2010). A systematic review and meta-analysis of the cognitive correlates of bilingualism. Review of Educational Research, 80(2), 207-245.

Abutalebi, J., \& Green, D. (2007). Bilingual language production: The neurocognition of language representation and control. Journal of neurolinguistics, 20(3), 242-275.

Bak, T. H., Nissan, J.J., Allerhand, M.M., \& Deary, L. T. (2014). Does Bilingualism influence Cognitive Aging? Annals of Neurology, (75), 959-963.

Barac, R., \& Bialystok, E. (2012). Bilingual effects on cognitive and linguistic development: Role of language, cultural background, and education. Child development, 83(2), 413-422.

Bialystok, E., Craik, F. I., \& Freedman, M. (2007). Bilingualism as a protection against the onset of symptoms of dementia. Neuropsychologia, 45(2), 459-464.

Bialystok, E., Craik, F. I., \& Ruocco, A. C. (2006a). Dual-modality monitoring in a classification task: The effects of bilingualism and ageing. The Quarterly Journal of Experimental Psychology, 59(11), 1968-1983.

Bialystok, E., \& Shapero, D. (2005). Ambiguous benefits: The effect of bilingualism on reversing ambiguous figures. Developmental Science, 8(6), 595-604.

Bialystok, E., \& Martin, M. M. (2004a). Attention and inhibition in bilingual children: Evidence from the dimensional change card sort task. Developmental science, 7(3), 325-339. 
Bialystok, E., Craik, F. I., Klein, R., \& Viswanathan, M. (2004b). Bilingualism, aging, and cognitive control: evidence from the Simon task. Psychology and aging, 19(2), 290.

Bialystok, E., Craik, F. I., \& Ryan, J. (2006b). Executive control in a modified antisaccade task: Effects of aging and bilingualism. Journal of Experimental Psychology: Learning, Memory, and Cognition, 32(6), 1341.

Bialystok, E., \& Viswanathan, M. (2009). Components of executive control with advantages for bilingual children in two cultures. Cognition, 112(3), 494-500.

Birdsong, D. (2005). Nativelikeness and non-nativelikeness in L2A research. International Review of Applied Linguistics in Language Teaching, 43(4), 319-328.

Bunge, S. A., Dudukovic, N. M., Thomason, M. E., Vaidya, C. J., \& Gabrieli, J. D. (2002). Immature frontal lobe contributions to cognitive control in children: evidence from fMRI. Neuron, 33(2), 301-311.

Costa, A., Hernández, M., \& Sebastián-Gallés, N. (2008). Bilingualism aids conflict resolution: Evidence from the ANT task. Cognition, 106(1), 59-86.

Carroll, J. B. (1993). Human cognitive abilities: A survey of factor-analytic studies. Cambridge University Press.

DeKeyser, Robert M. "The robustness of critical period effects in second language acquisition." Studies in second language acquisition 22.04 (2000): 499-533.

Emmorey, K., Luk, G., Pyers, J. E., \& Bialystok, E. (2008). The source of enhanced cognitive control in bilinguals evidence from bimodal bilinguals. Psychological Science, 19(12), 1201-1206.

Eriksen, C. W. (1995). The flankers task and response competition: A useful tool for investigating a variety of cognitive problems. Visual Cognition, 2(2-3), 101-118.

Gathercole, V. C. M., Thomas, E. M., Kennedy, I., Prys, C., Young, N., Guasch, N. V.,... \& Jones, L. (2014). Does language dominance affect cognitive performance in bilinguals? Lifespan evidence from preschoolers through older adults on card sorting, Simon, and metalinguistic tasks. Frontiers in psychology, 5.

Jacoby, A., Gamble, C., Doughty, J., Marson, A., \& Chadwick, D. (2007). Quality of life outcomes of immediate or delayed treatment of early epilepsy and single seizures. Neurology, 68(15), 1188-1196.

Johnson, J. S., \& Newport, E. L. (1989). Critical period effects in second language learning: The influence of maturational state on the acquisition of English as a second language. Cognitive psychology, 21(1), 60-99.

Kalia, V., Wilbourn, M. P., Ghio, K. (2014). Better early or Late? Examination of influence of age of exposure and language proficiency on executive function in Early and Late Bilinguals, Journal of Cognitive Psychology, 37-41.

Kovelman, I., Baker, S. A., \& Petitto, L. A. (2008). Bilingual and monolingual brains compared: a functional magnetic resonance imaging investigation of syntactic processing and a possible "neural signature" of bilingualism. Journal of cognitive neuroscience, 20(1), 153-169.

Kovelman, I., Baker, S. A., \& Petitto, L. A. (2008). Bilingual and monolingual brains compared: a functional magnetic resonance imaging investigation of syntactic processing and a possible "neural signature" of bilingualism. Journal of cognitive neuroscience, 20(1), 153-169.

Luk, G., De Sa, E., \& Bialystok, E. (2011). Is there a relation between onset age of bilingualism and enhancement of cognitive control?. Bilingualism: Language and Cognition, 14(04), 588-595.

Olson, D. R., \& Bialystok, E. (2014). Spatial cognition: The structure and development of mental representations of spatial relations. Psychology Press.

Poulin-Dubois, D., Blaye, A., Coutya, J., \& Bialystok, E. (2011). The effects of bilingualism on toddlers' executive functioning. Journal of experimental child psychology, 108(3), 567-579.

Unsworth, S. (2012). Testing for crosslinguistic influence and exposure effects in the bilingual acquisition of specific indefinite objects. In Proceedings of the 36th annual Boston University Conference on Language Development (pp. 633-645).

Transparant Language. (2015). Retrieved June 2015, from Transparant Language: http://www.transparent.com/about/company_info.html. 